\title{
La Société Française de Physique célèbre les 100 ans \\ de la supraconductivité
}

L'année 2011 marque le 100 anniversaire de la découverte de la supraconductivité dans le mercure, le 8 avril 1911 à Leyde, aux Pays-Bas, par Heike Kamerlingh Onnes et son équipe. Cette découverte a été rendue possible par la liquéfaction de I'hélium, trois ans auparavant, et couronnée du prix Nobel en 1913.

La supraconductivité est la première manifestation d'un état quantique à l'échelle macroscopique dans la matière condensée. Elle se caractérise par la perte de toute résistance électrique en dessous de la « température critique » du matériau, $T_{\mathrm{C}}$, et par l'exclusion du champ électromagnétique.
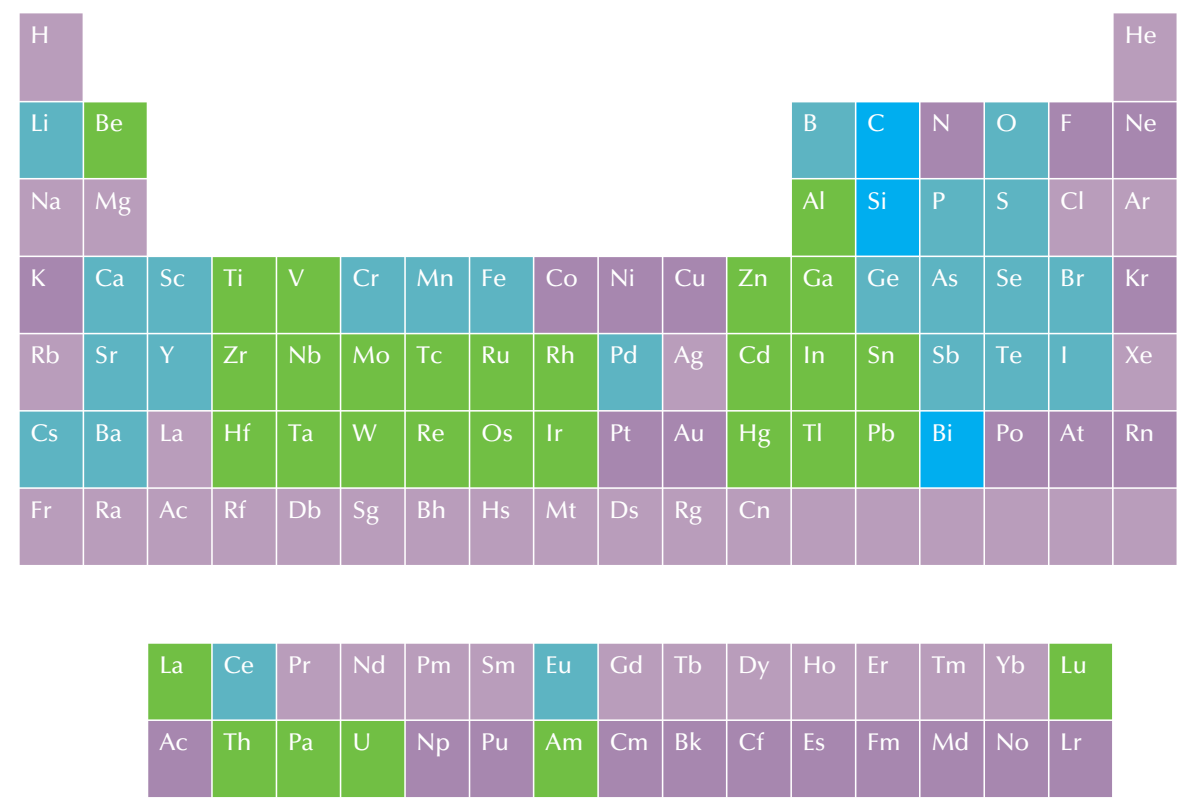

Les éléments supraconducteurs. Loin d'être rare, la supraconductivité se manifeste dans tous les éléments colorés en vert. En plus, 24 autres éléments sont supraconducteurs sous haute pression (bleu clair). Le carbone et le silicium deviennent supraconducteurs lors d'un dopage adéquat. Le bismuth est supraconducteur sous forme de couche mince ou de nanofil.
Bien que centenaire, la recherche sur la supraconductivité continue d'être ponctuée de découvertes spectaculaires, remettant en cause les paradigmes de la physique du solide. Ainsi, 1986 vit la découverte, par Georg Bednorz et Alex Müller, de la supraconductivité dans les cuprates à haute température critique. Là où l'on croyait que des $T_{\mathrm{c}}$ supérieures à $25-30 \mathrm{~K}$ étaient inatteignables à cause de la nature du mécanisme de la supraconductivité, celle des cuprates apparaît dans des oxydes isolants, qui deviennent conducteurs lorsque l'on y introduit, par dopage chimique, des porteurs de charge. Aussi récemment que 2008, la découverte de la supraconductivité dans des composés à base de fer a fait sensation.

Le lien de la recherche française avec la supraconductivité a toujours été très fort, et le reste aujourd'hui. L'influence du groupe d'Orsay et de Pierre-Gilles de Gennes sur le sujet garde toute son importance à travers le monde à ce jour, le livre fondateur de de Gennes [1] étant toujours le principal ouvrage didactique sur le sujet. Suite à l'une de ses propositions, la France a été le théâtre de la mise en évidence du réseau de vortex par diffraction neutronique par Daniel Cribier et ses collaborateurs à Saclay en 1964 ; puis ce furent les découvertes des chalcogénures de plomb, supraconducteurs bidimensionnels à très fort champ critique (Roger Chevrel, Marcel Sergent et Jacques Prigent, Rennes, 1971) et de la supraconductivité dans les sels organiques de Bechgaard (Denis Jérôme, Orsay, 1978). 
